\title{
Low-Complexity Howling Detection based on Statistical Analysis of Temporal Spectra
}

\author{
Jae-Won Lee ${ }^{1}$ and Seung Ho Choi ${ }^{2, *}$ \\ ${ }^{1}$ Graduate School of NID Fusion Technology \\ Seoul National University of Science and Technology, Seoul 139-743, Korea \\ ${ }^{2}$ Department of Electronic and IT Media Engineering \\ Seoul National University of Science and Technology, Seoul 139-743, Korea \\ E-mail: shchoi@seoultech.ac.kr \\ * Corresponding author
}

\begin{abstract}
Howling is generated due to acoustic feedback circuit and is difficult to predict since it varies depending on the indoor environment. Furthermore, it is hard to distinguish between original and howling signals in real-time. In this paper, we propose a novel howling detection method based on statistical analysis of temporal power spectra. The proposed method is shown experimentally to be suitable for howling detection.
\end{abstract}

Keywords: Howling, Temporal power spectra, Howling suppression, Acoustic feedback circuit

\section{Introduction}

Howling is generated in audio amplifier system such as sound reinforcement, mobile device and hearing aids when an acoustic feedback circuit (AFC) [1-7] diverges by positive feedback $[8,9]$. Figure 1 shows an example of howling occurrence in a music signal [1]. Moreover, the howling varies depending on the overall environment such as the positions of microphones and loudspeakers, room shape and arrangement, the position and movement of talker, room temperature [1]. Therefore, it is difficult to predict the howling [1]. Furthermore, it is hard to distinguish original and howling signals before recognizing howling sound.

To suppress howling, gain or frequency control methods have been developed, which uses equalizer [10-13], frequency shifter [14] and notch filters [15-20]. For the detection of howling frequency, several techniques have been developed such as least the mean square (LMS) method [21-23]. Recently, notch filters have been employed, which suppresses howling by reducing the gain at a specific frequency [15-20]. However, these filters must accurately detect the howling frequency and require a large amount of operations [21,22].

In this paper, we present a novel method for the detection of howling frequency based on statistical analysis of temporal power spectra. The remainder of this paper is organized as follows. Statistical properties of the howling are presented in Section 2. The proposed howling detection method is described in Sections 3. Comparison of complexities between the conventional method and the proposed method is given in Section 4. Experimental results are illustrated in Section 5. Finally, conclusions are given in Section 5. 


\section{Statistical Analysis of Howling}

The howling typically occurs when the original signal energy is looped back continuously growing in intensity at peaks of the frequency response. The spectrogram in Figure 1 shows an example of howling occurrence in an actual music signal.

The AFC can easily diverge due to a positive feedback circuit. The microphone input signal $x(t)$ is amplified by gain $g$ and then the loudspeaker output signal $y_{0}(t)$ is generated as shown in Figure 2(a) [1]. The $\mathrm{y}_{0}(\mathrm{t})$ makes the multiple reflection signals $\left\{\mathrm{y}_{\mathrm{i}}(\mathrm{t})\right\}$ which are summed to the feedback signal $\mathrm{y}(\mathrm{t})=\sum_{\mathrm{i}=1}^{\mathrm{n}} \alpha_{\mathrm{i}} \mathrm{y}_{0}\left(\mathrm{t}-\tau_{\mathrm{i}}\right)$ [1]. These signals are again entered to the microphone, where $\alpha_{i}$ is the attenuation factor of indoor wall and $\tau_{\mathrm{i}}$ is delay time.

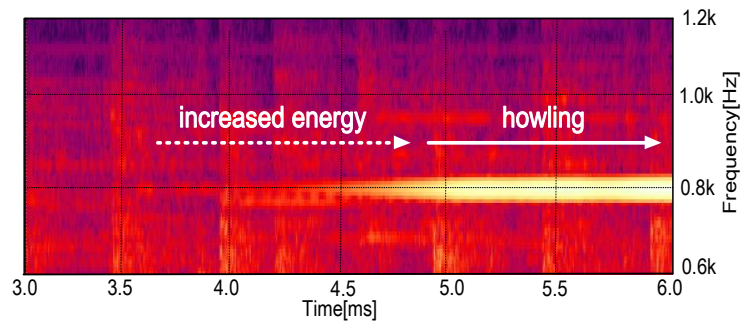

Figure 1. Example of occurrence of howling in a music signal (spectrograms)

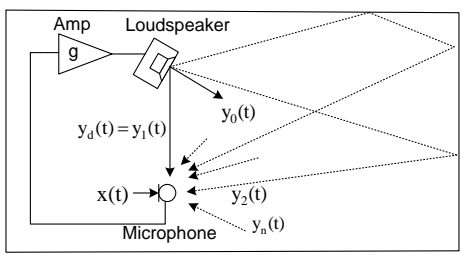

(a)

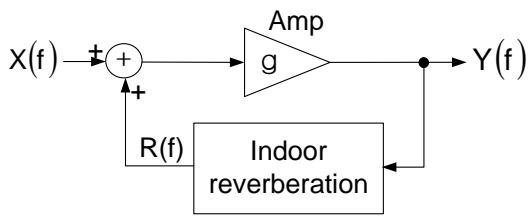

(b)

Figure 2. Howling model. (a) AFC formation in the indoor reflection environment, (b) AFC model

The AFC model is shown as Figure 2(b) and the transfer function can be represented as $\mathrm{H}(\mathrm{f})=\mathrm{Y}(\mathrm{f}) / \mathrm{X}(\mathrm{f})=\mathrm{g} /(1-\mathrm{gR}(\mathrm{f}))$, where $\mathrm{R}(\mathrm{f})$ is room impulse response. From the phase response $\angle \mathrm{H}(\mathrm{f})$ of Eq. (1), frequencies at $\angle \mathrm{H}(\mathrm{f})=2 \pi \mathrm{m}$ become potential howling frequencies (PHFs), where $\mathrm{m}$ is an integer [1-4].

First, we examined the temporal variation of power spectra, $V(f)=X_{\text {curr }}(f)-X_{\text {prev }}(f)$, where $\mathrm{X}_{\text {curr }}(\mathrm{f})$ and $\mathrm{X}_{\text {prev }}(\mathrm{f})$ are current and previous FFT spectra, respectively. In stable condition, as can be seen in Figure 3, the V(f) can be seen as random and the histogram looks like Gaussian distribution. Figure 4 shows the temporal variations of $V(f)$ over some frequency range. In stable condition, the V(f) varies continuously, whereas gets small at a specific frequency in howling condition. 


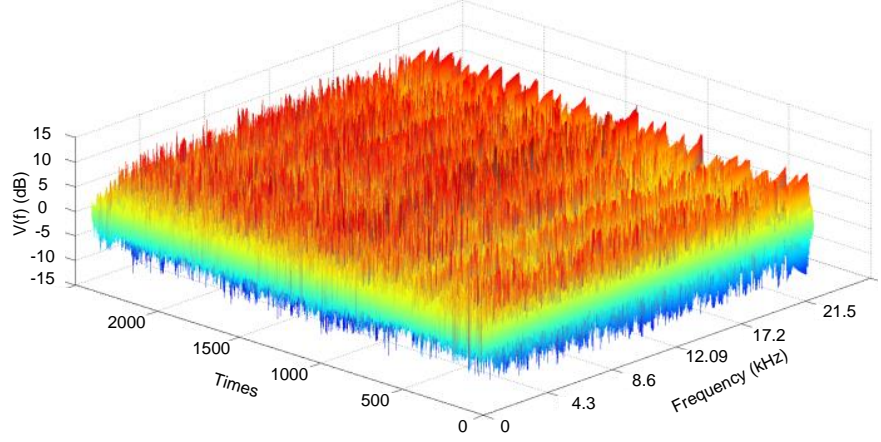

(a)

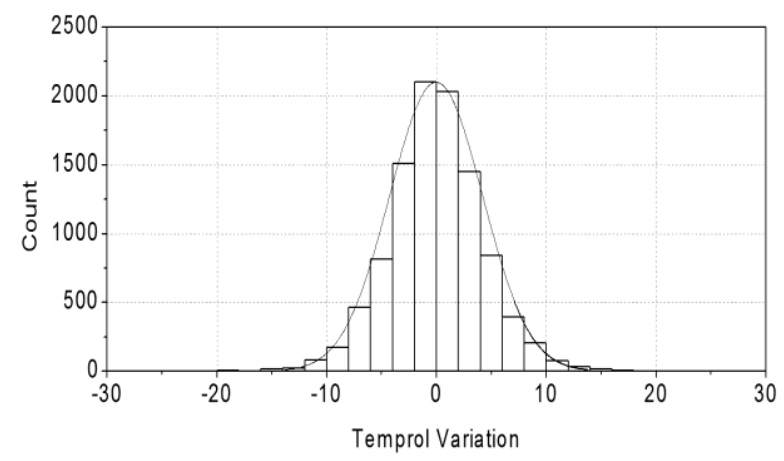

(b)

Figure 3. Examples of $\mathrm{V}(\mathrm{f})$ in stable condition. (a) Waterfall diagram, (b) histogram

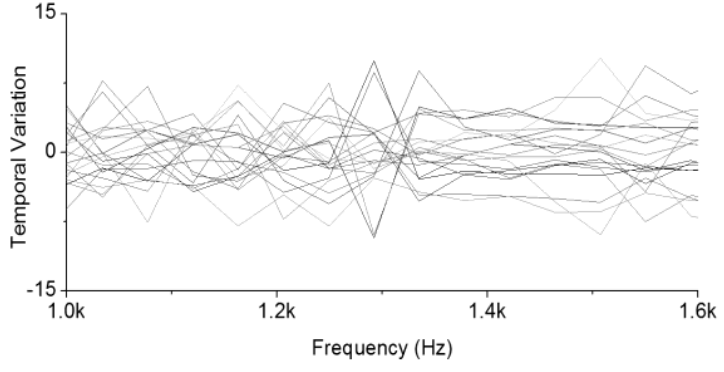

(a)

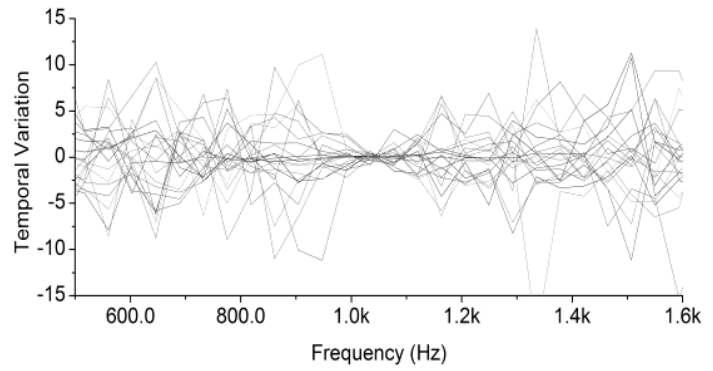

(b)

Figure 4. Example of $\mathrm{V}(\mathrm{f})$. (a) In stable condition, (b) in howling condition

In stable and howling conditions, the examples of standard deviations (STDs) of V(f) are shown in Figures 5(a) and 5(b), respectively. In howling condition, both V(f) and STD(f) gets small compared to those in stable condition. Especially, the differences in the STD(f) values between stable and howling conditions are noticeable. Therefore, we utilized the $\operatorname{STD}(\mathrm{f})$ values to detect howling frequency. 


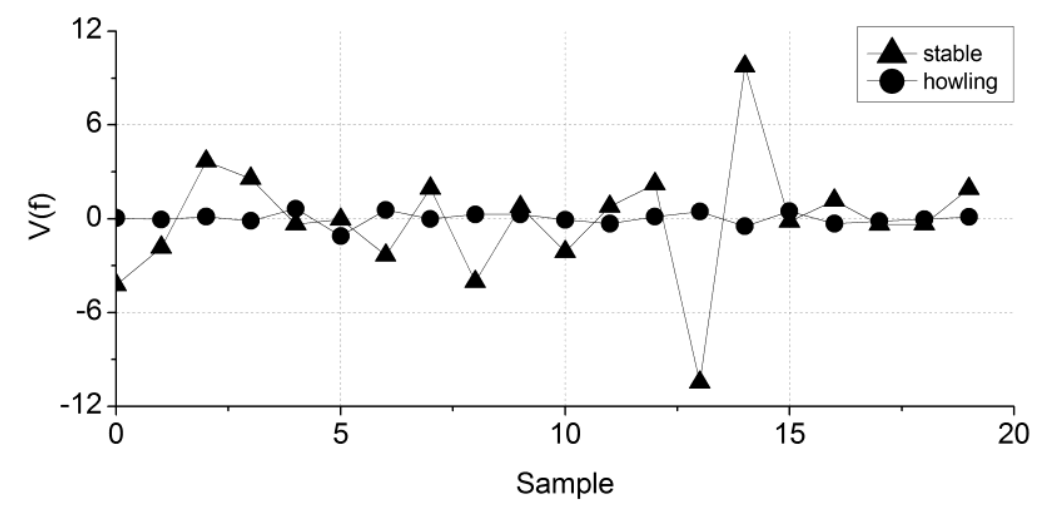

(a)

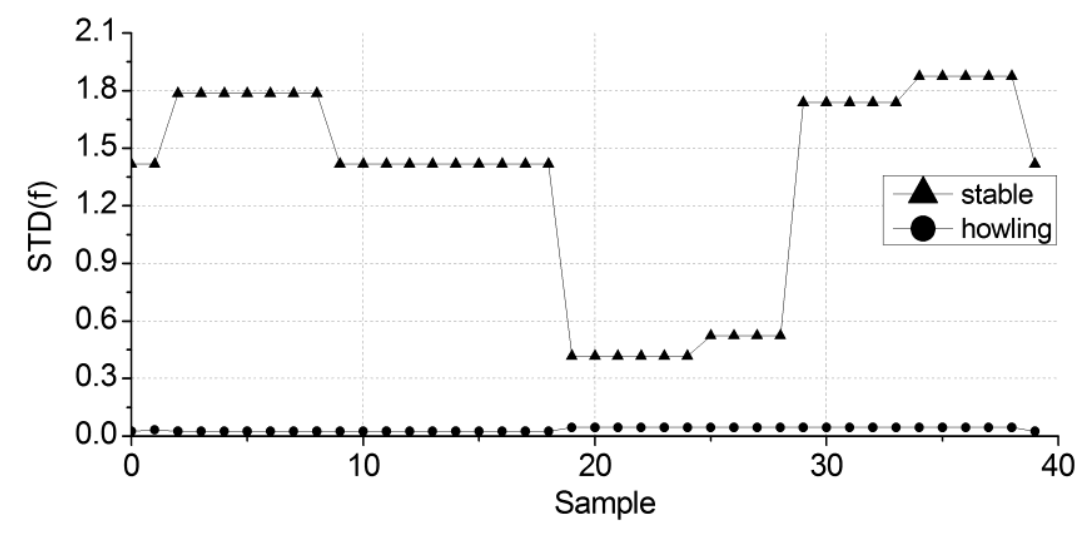

(b)

Figure 5. Examples of $\mathrm{V}(\mathrm{f})$ and $\operatorname{STD}(\mathrm{f})$ at around $1 \mathrm{kHz}$. (a) In stable condition, (b) in howling condition

\section{The Proposed Howling Detection Algorithm}

Figure 6 shows the overall block diagram of the proposed howling detection algorithm. First, V(f) is calculated and is recorded in the queue buffer. Also, the peak frequency is detected at the same time using the FFT spectrum X(f). The moving average value of V(f), $\mathrm{A}(\mathrm{f})$, is calculated and is recorded in another queue buffer. Then, $\operatorname{STD}(\mathrm{f})$ is computed using the $A(f)$. If the $\operatorname{STD}(f)$ is smaller than the threshold $\operatorname{STD}_{\text {th }}$, then the counter, $S_{c}(f)$, is increased, else is decreased. 


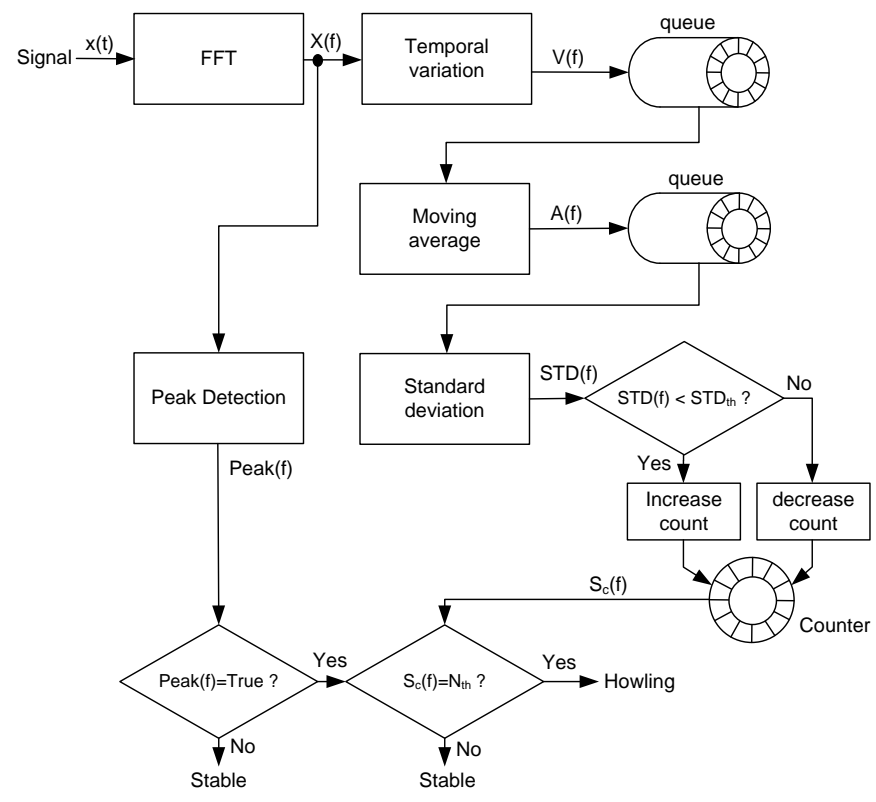

Figure 6. Overall block diagram of the proposed algorithm

In stable condition, the proposed algorithm may detect the peaks but does not detect howling since the condition $\mathrm{S}_{\mathrm{c}}(\mathrm{f})=\mathrm{N}_{\mathrm{th}}$ is not satisfied as shown in Figures 7(a) and 7(c). However, in howling condition, both peak detection and howling detection are occurred since the condition $S_{c}(f)=N_{t h}$ is satisfied as shown in Figures $7(b)$ and $7(d)$.

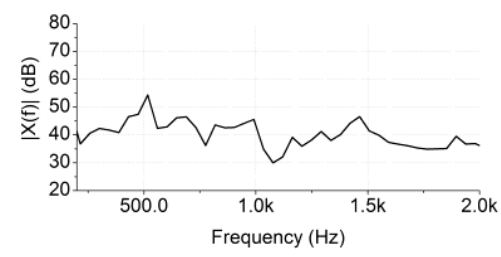

(a)

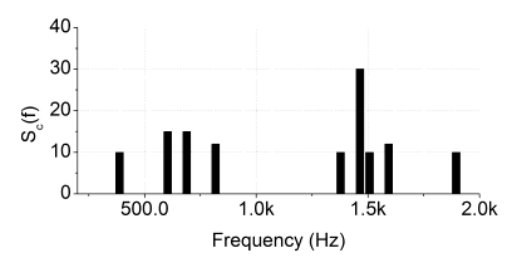

(c)

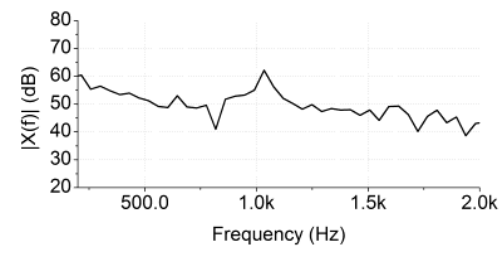

(b)

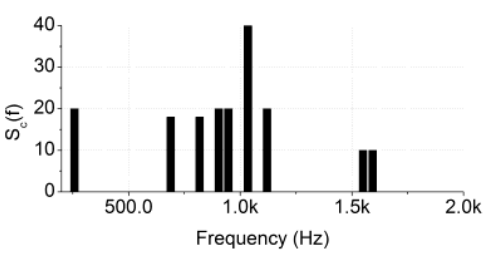

(d)

Figure 7. Example of peak and howling detection ( $\mathrm{N}_{\mathrm{th}}=40$ ). (a) FFT spectrum in stable condition, (b) FFT spectrum in howling condition, (c) $S_{c}(f)$ in stable condition, (d) $\mathrm{S}_{\mathrm{c}}(\mathrm{f})$ in howling condition 


\section{Comparison of Complexities}

In order to evaluate the complexity of the prosed algorithm, time complexity is employed. Furthermore, we used Big-O notation [24], which is used to efficiently describe the time complexity. For the comparison with the conventional method, first, LMS algorithm is analyzed as shown in Table 1 and the complexity can be represented as

$$
\mathrm{O}_{\mathrm{LMS}}(\mathrm{M})=\mathrm{M}^{2}
$$

Table 1. Complexity of LMS algorithm

\begin{tabular}{|c|c|c|c|c|}
\hline Equation & Multiplication & Addition & Iteration & Sum \\
\hline $\mathbf{w}(\mathrm{n})+$ & & 1 & M & \multirow{4}{*}{$M^{2}+4 M$} \\
\hline$\mu \cdot(\ldots)$ & 1 & & $\mathrm{M}$ & \\
\hline$\varepsilon(\mathrm{n})=\mathrm{d}(\mathrm{n})-\mathbf{w}(\mathrm{n}) \mathbf{x}(\mathrm{n})$ & $\mathrm{M}$ & 1 & $\mathrm{M}$ & \\
\hline$(\ldots) \cdot \mathbf{x}(n)$ & 1 & & M & \\
\hline
\end{tabular}

The complexity of the proposed algorithm is shown in Table 2. The square root operation is approximated by Babylonian method [25]. For computation per sample, $1 / \mathrm{N}_{\mathrm{FFT}}$ is multiplied. As a result, the complexity can be represented as

$$
\mathrm{O}_{\mathrm{STD}}\left(\mathrm{N}_{\mathrm{FFT}}\right)=\mathrm{N}_{\mathrm{FFT}} \log _{2}\left(\mathrm{~N}_{\mathrm{FFT}}\right)
$$

\begin{tabular}{|c|c|c|c|c|c|c|}
\hline Composition & Equation & $\begin{array}{c}\text { Equation } \\
\text { Details } \\
\end{array}$ & Multiplication & Addition & Iteration & Sum \\
\hline FFT & & & & & 1 & $\mathrm{~N}_{\mathrm{FFT}} \log _{2}\left(\mathrm{~N}_{\mathrm{FFT}}\right)$ \\
\hline \multirow{2}{*}{ Mean } & \multirow{2}{*}{$\mathrm{MA}=\frac{1}{\mathrm{~N}_{\mathrm{Q}}} \Sigma_{\mathrm{i}=0}^{\mathrm{N}_{\mathrm{O}}-1} \mathrm{x}_{\mathrm{i}}$} & $\frac{1}{\mathrm{~N}_{\mathrm{Q}}}(\cdots)$ & 1 & & \multirow{2}{*}{1} & \multirow{2}{*}{$\mathrm{N}_{\mathrm{Q}}$} \\
\hline & & $\sum_{\mathrm{i}=0}^{\mathrm{N}_{\mathrm{o}}-1}(\ldots)$ & & $\mathrm{N}_{\mathrm{Q}}-1$ & & \\
\hline \multirow{3}{*}{ Variance } & \multirow{3}{*}{$\operatorname{STD}^{2}=\frac{1}{N_{Q}} \sum_{\mathrm{i}=0}^{N_{0}-1} x_{i}^{2}$} & $\Sigma_{\mathrm{i}=0}^{\mathrm{N}_{0}-1}(\ldots)$ & 1 & & \multirow{3}{*}{1} & \multirow{3}{*}{$2 \mathrm{~N}_{\mathrm{Q}}+2$} \\
\hline & & $\Sigma_{\mathrm{i}=0}^{\mathrm{N}_{\mathrm{o}}-1} \mathrm{x}_{\mathrm{i}}^{2}$ & $\mathrm{~N}_{\mathrm{Q}}$ & $\mathrm{N}_{\mathrm{Q}}-1$ & & \\
\hline & & $(\ldots)-\mathrm{MA}^{2}$ & 1 & 1 & & \\
\hline $\begin{array}{c}\text { Square } \\
\text { Root }\end{array}$ & $\mathrm{x}_{\mathrm{n}+1}=0.5\left(\mathrm{x}_{\mathrm{n}}+\frac{\mathrm{a}}{\mathrm{x}_{\mathrm{n}}}\right)$ & $0.5 \cdot(\ldots)$ & 1 & & 10 & 30 \\
\hline
\end{tabular}

Table 2. Complexity of proposed algorithm

As a result, from (1) and (2), the complexity of the proposed algorithm is very low compared with the conventional LMS algorithm. 


\section{Experiments}

Figure 8 shows the configuration for the experiments, which employed the electric reverberator to generate the indoor sound. The signal block provided a music sound signal. The feedback circuit and system gain were implemented with digital signal processors as shown in Figure 9. We set $\mathrm{N}_{\mathrm{FFT}}$ and $\mathrm{N}_{\mathrm{Q}}$ as 2048 and 40, respectively in the experiment. The howling detector was operated in real-time.

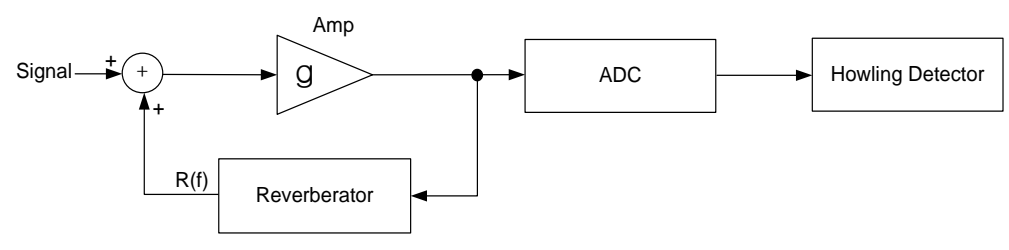

Figure 8. Configuration of the experiments

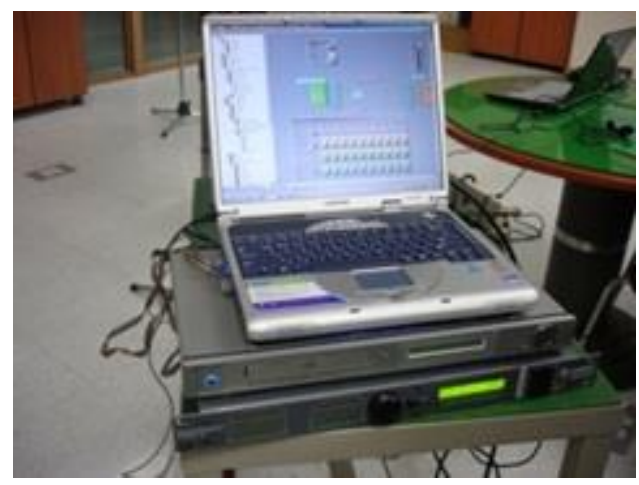

Figure 9. DSP equipment and howling detector.

Figure 10 shows the experimental results with the reverberation time of $0.7 \mathrm{sec}$. We can notice that the proposed method successfully detect the howling at two positions. Similar results can be seen in Figures. 11, 12 and 13, with the reverberation times of 1.0, 1.7 and 3.0 sec.

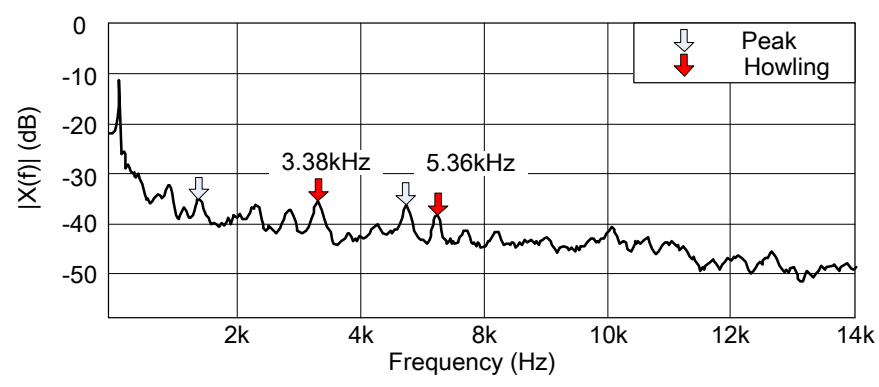

(a) 


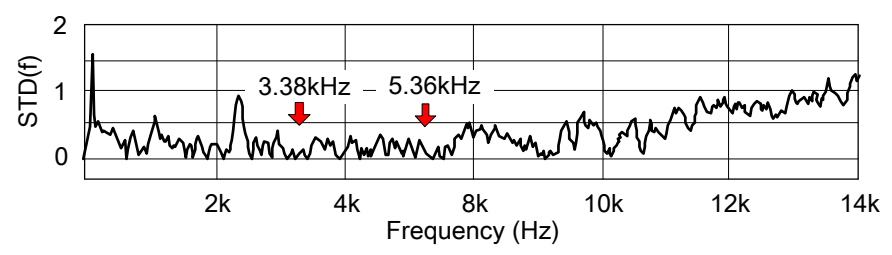

(b)

Figure 10. Howling detection (at $3.38 \mathrm{kHz}, 5.38 \mathrm{kHz}$ ) with the reverberation time of 0.7 sec. (a) FFT spectrum, (b) STD(f)

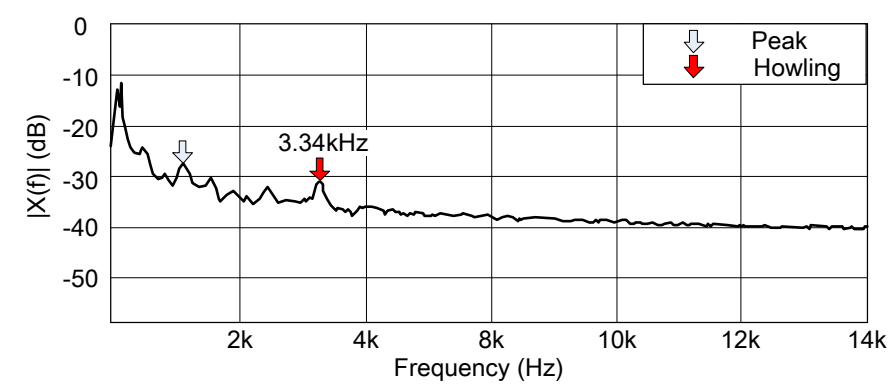

(a)

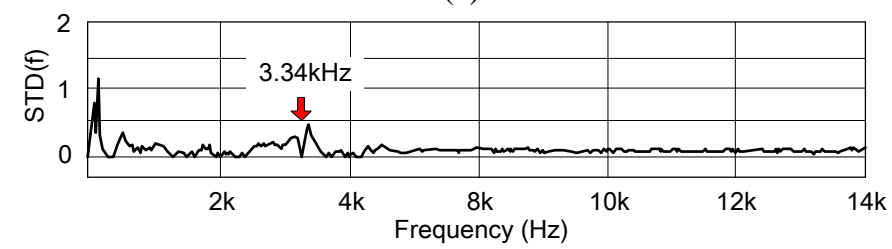

(b)

Figure 11. Howling detection (at $3.34 \mathrm{kHz}$ ) with the reverberation time of 1.0 sec. (a) FFT spectrum, (b) STD(f)

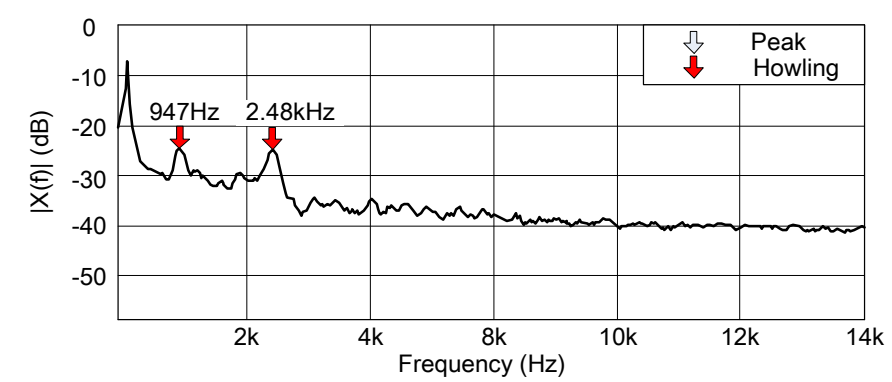

(a)

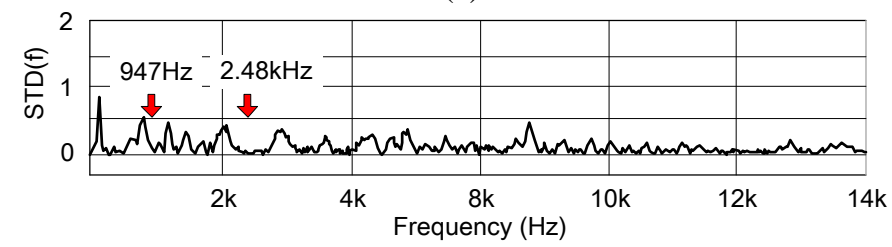

(b)

Figure 12. Howling detection (at $947 \mathrm{kHz}, 2.48 \mathrm{kHz}$ ) with the reverberation time of 1.5 sec. (a) FFT spectrum, (b) STD(f) 


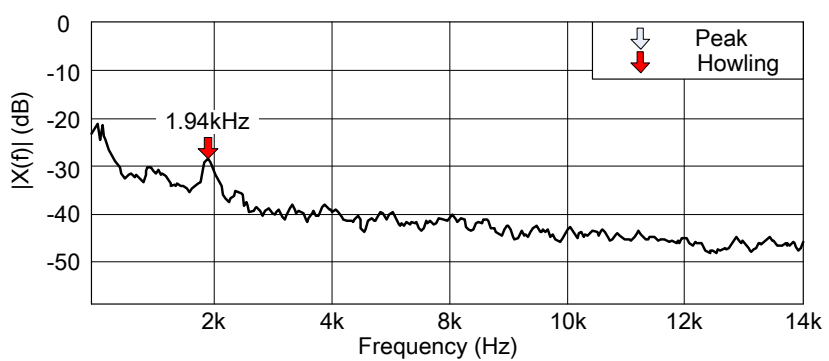

(a)

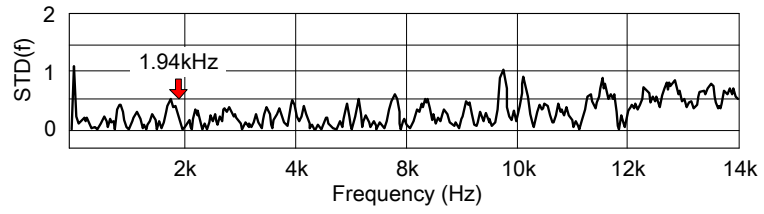

(b)

Figure 13. Howling detection (at $1.94 \mathrm{kHz}$ ) with the reverberation time of 3.0 sec. (a) FFT spectrum, (b) STD(f)

\section{Conclusion}

In this paper, we presented a low-complexity howling detection method based on statistical analysis of temporal variation in power spectra. The proposed method was evaluated for various reverberation time conditions and was implemented. In addition, from the complexity analysis, the proposed algorithm is shown to be suitable for howling detection in real-time.

\section{Acknowledgements}

This study was (partially) supported by Seoul National University of Science and Technology.

\section{References}

[1] J. -W. Lee, S. H. Choi and H. C. Park, "A howling margin enhancement method using all-pass filters with phase dispersion", Information Journal, vol. 16, no. 1(B), (2013) January, pp.795-800.

[2] H. S. Antman, "Extension to the theory of howlback in reverberant rooms", Journal of the Acoustical Society of America (Letters to the Editor), vol. 39, no. 2, (1996), pp. 399.

[3] R. Waterhouse, "Theory of howl-back in reverberant rooms", Journal of the Acoustical Society of America (letters to the Editor), vol. 37, (1965), pp. 921.

[4] D. Troxel, "Understanding Acoustic Feedback \& Suppressors", Rain Note, Rain Co. (2005).

[5] C. J. Chun, H. K. Kim and S. R. Kim, "Enhanced reproduction of auditory image recorded using closely spaced stereo microphones", Information: an International Interdisciplinary Journal, vol. 16, no. 3(B), (2013) March, pp. 3275-3284.

[6] J. H. Park, H. K. Kim, M. B. Kim and S. R. Kim, "A user voice reduction algorithm based on binaural signal separation for portable digital imaging devices", IEEE Trans. on Cons. Elect., vol.58, no.2, (2012), pp.679-684.

[7] J. A. Kang, C. J. Chun, H. K. Kim, M. B. Kim and S. R. Kim, "A smart background music mixing algorithm for portable digital imaging devices", IEEE Trans. on Cons. Elect., vol. 57, no. 3, (2011) pp. 1258-1263.

[8] H. Nyquist, "Regeneration theory", Bell Syst. Tech. J., vol. 11, (1932), pp. 126-147.

[9] E. Lindberg, "The Barkhausen criterion (observation)", Proc. the 18th IEEE Workshop on Nonlinear Dynamics of Electronics System, (2010) Dresden, Germany, pp. 15-18.

[10] S. M. Kuto, W. S. Gan and F. -L. Shau, "Design and synthesis of the audio equalizers", IEEE 7th International Conference on Signal Processing, (2004), pp. 579-582.

[11] W. Conner, "Theoretical and practical consideration in the equalization of sound systems", Journal of Audio Engineering Society, vol. 15, (1967) April, pp.194-198. 
[12] E. P. Gonzalez and J. Reiss, "An automatic maximum gain normalization technique with applications to audio mixing”, Audio Engineering Society 124th Convention, Preprint 4711 (2008).

[13] T. T. Quatieri and R. J. McAulay, "Peak-to-RMS reduction of speech based on a sinusoidal model", IEEE Transaction on Signal Processing, vol. 39, no. 2, (1991), pp.273-288.

[14] M. R. Schroeder, "Improvement of acoustic feedback stability by frequency shifting", Journal of the Acoustical Society of America, vol. 36, no. 9, (1932), pp. 1718-1724.

[15] W. Loetwassana, R. Punchalard, A. Lorsawatsiri and J. Koseeyaporn, "Adaptive howling suppressor in audio amplifier system”, Proceedings of Asia-Pacific Conference on Communications, (2007), pp. 445-448.

[16] P. Gil-Cacho, "Regularized adaptive notch filters for acoustic howling suppression", Proceedings of EUSIPCO, (2009), pp. 2574-2578.

[17] H. Cao, J. Liu and W. Zhang, "A combined de-correlation method for acoustic feedback cancellation in hearing aids", World Congress on Computer Science and Information Engineering, (2009) March; Los Angeles, CA, pp. 220-224.

[18] A. Nehorai, "A minimal parameter adaptive notch filter with constrained poles and zeros", IEEE Transactions on Acoustics, Speech, and Signal Processing, vol. 33, (1995), pp. 983-996.

[19] T. -H. Choi, B. -U. Park and H. -Y. Kim, "Quasi-linear phase adaptive notch filter for howling suppression", Proceedings of Spring Meeting of the Acoustical Society of Korea, vol. 20, no. 2, (2001), pp.245-248.

[20] C. J. Chun, H. K. Kim, S. H. Choi, S. J. Jang and S. P. Lee, "Sound source elevation using spectral notch filtering and directional band boosting in stereo loudspeaker reproduction", IEEE Transactions on Consumer Electronics, vol. 57, no. 4, (2011) November, pp. 1915-1920.

[21] J. Wei, L. Du, Z. Chan and F. Yin, “A new algorithm for howling detection”, IEEE International Symposium on Circuits and Systems, vol. 4, (2003), pp. 409-411.

[22] S. Ibaraki, H. Furukawa and H. Noono, "Pre-howling howlback detection method", IEEE International Conference on Acoustics Speech and Signal Processing, (1986), pp. 941-944.

[23] E. T. Patrons, Jr., "Electronic Detection of Acoustic Feedback and Automatic Sound System Gain Control", Journal of Audio Engineering Society, vol. 26, no. 5, (1978), pp. 323-326.

[24] T. Cormen, C. Leiserson, R. Rivest and C. Stein, "Introduction to Algorithms", Second Edition (2001).

[25] M. Campbell-Kelly, “Origin of Computing”, Scientific American, (2009) September.

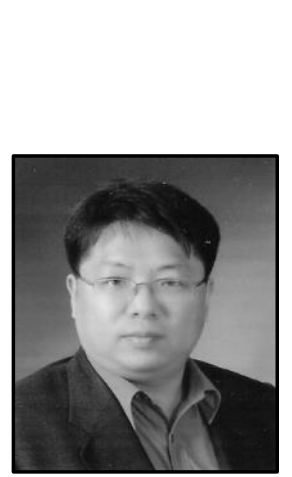

\section{Authors}

\section{Jae-Won Lee}

Jae-Won Lee received as B. S. degree in Electronic Engineering from Mungji University, Korea in 1996. He received M. S degree in Electronic Engineering form Seoul National University of Technology, Korea in 2007. He then received $\mathrm{Ph} . \mathrm{D}$. degree in Electronic and Information Engineering form Seoul National University of Science and Technology, Korea in 2012. He was a R\&D chief at Donghwa Electric Sound Company, Korea, from 2004 and 2012. Since June 2012, he has been with Bosung Electronics Co. Ltd., as a director. His current research interests include sound field control, audio system optimization, audio signal processing.

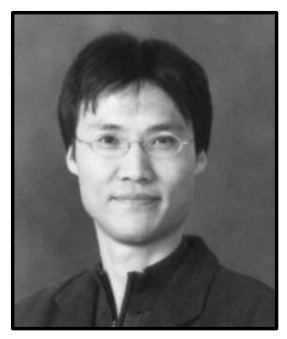

\section{Seung Ho Choi}

Seung Ho Choi received a B.S. degree in Electronic Engineering from Hanyang University, Korea in 1991. He then received both M.S. and Ph.D. degrees in Electrical Engineering from Korea Advanced Institute of Science and Technology (KAIST), Korea in 1993 and 1999, respectively. He was a senior researcher at Samsung Advanced Institute of Technology, Korea, from 1996 to 2002. He was a visiting professor at University of Florida, USA, from 2008 to 2009. Since August 2002, he has been with the Department of Electronic and IT Media Engineering at Seoul National University of Science and Technology as a professor. His current research interests include audio signal processing, 3D audio, speech and audio coding, speech recognition, human-computer interaction. E-mail: shchoi@ seoultech.ac.kr. 